\title{
EL PRESENTE. FASCINACIÓN Y DECEPCIÓN EN LA ESCRITURA ENSAYÍSTICA DE BAUDELAIRE
}

\author{
Carlos Surghi \\ Instituto de Humanidades \\ Universidad Nacional de Córdoba \\ Consejo Nacional de Investigaciones Científicas y Técnicas \\ carlossurghi@yahoo.com.ar
}

\begin{abstract}
Resumen: El presente trabajo propone una lectura de la estética de Baudelaire desde tres figuras que conforman una fantasmática del sujeto de escritura: la fascinación, la expectativa y la decepción ante "lo nuevo". Por medio de ellas, evidentes en los ensayos, la prosa y la poesía de Baudelaire, como así también en sus figuraciones biográficas, sus registros del presente y su veneración de la tradición, es que las imágenes, el culto de la analogía y la melancolía ante la distinción de aquel objeto que desaparece, permiten reconocer una definición de "lo moderno" que no es más que la embriagues de la interpretación. De este modo, la estética baudeleriana podría entenderse como una vitalidad que se consume, una afirmación que en si misma lleva su principio de negación, una orientación que a la vez fascina y decepciona, pero que inevitablemente, conduce hacia el silencio de la ruina como figura metafísica en el presente.
\end{abstract}

Palabras clave: Fascinación, Presente, Escritura, Ensayo, Estética.

\begin{abstract}
The present work proposes a reading of Baudelaire's aesthetics from three figures that make up a fantasmatic of the writing subject: the fascination, the expectation and the disappointment before "the new". Through them, evident in the essays, the prose and poetry of Baudelaire, as well as in his biographical figurations, his records of the present and his veneration of tradition, is that the images, the cult of analogy and melancholy before the distinction of that object that disappears, they allow to recognize a definition of "the modern" that is not more than the inebriation of the interpretation. In this way, the Baudelairean aesthetic could be understood as a vitality that is consumed, an affirmation that in itself carries its principle of negation, an orientation that at once fascinates and disappoints, but that inevitably leads to the silence of ruin as metaphysical figure in the present.
\end{abstract}

Keywords: Fascination, Present, Writing, Essay, Aesthetics. 
Baudelaire amó el presente con la complejidad que esto trae aparejado. Se sintió tan atraído por él que terminó transformándose en su intérprete. Es más, esa atracción pronto se volvió fascinación, lo cual lo llevó a imaginar en su banalidad las formas perdurables para el futuro. Sin embargo, al poco tiempo el presente resultó cruel; en el mismo espejo donde reflejara su rostro hecho de artistas que persiguen lo nuevo en lo exótico y en lo cosmopolita lo más fiel a su experiencia, Baudelaire se vio también incomprendido, abandonado por la propia creación que había conjurado. Al igual que el tiempo de una ciudad, el presente es un itinerario que va desde el centro hacia su periferia, desde la fascinación de sus vidrieras hacia la decepción de los barrios pobres. Si extremáramos la interpretación siguiendo una orientación biográfica podríamos decir que Baudelaire es ese cisne extraviado del poema de Las flores del mal, una actriz interpretando a Andrómaca que dejaba caer su máscara, o el poeta en el país de la indiferencia que trastabillaba en una iglesia de Bélgica, como el albatros que torpemente camina en la cubierta de un barco, desmoronándose al igual que los pasajes de París al dejar paso al anonimato y el olvido de los grandes bulevares. En cada una de esas imágenes, materiales y a la vez íntimas, personales, está Baudelaire en cada instante del presente.

Sin embargo, el presente de Baudelaire es mucho más que las deudas continuas y humillantes, es mucho más que un 
proceso estúpido por ofensa a la moral y la decepción de una serie de episodios que colmaran de amargura cualquier expectativa en sus últimos días. El limbo del mutismo y las absortas miradas parecen ser finalmente la imagen del presente. La amarga contradicción, su destino: a la voz de su tiempo la ausencia de voz en el mismísimo presente de esa voz. ¿Qué queda entonces de Baudelaire? La ruina, el spleen, la ciudad y la atención de quien deambula en busca de la forma de aquello que siempre cambia en lo inmediato; el sello de lo distintivo. Aun así, al momento de rastrear el origen de esa distinción, ¿cuánto hay en estas figuras de prolongada meditación o de espontáneo rapto? ¿Cuánto queda en ellas del presente como fascinación y decepción?

Desde el principio Baudelaire desconfió de los sistemas de pensamiento. Ante la tentación de la totalidad prefirió los inciertos fragmentos de publicaciones periódicas, encargos, traducciones y por supuesto, la silenciosa y persistente confección de máscaras, disfraces y escenas melodramáticas que recaían sobre él mismo. La fascinación entonces por el presente puede pensarse como un desafío que lo premia con la distinción de ser el primero en hablar de lo nuevo. Como la soledad sádica, la crítica en Baudelaire es prepotencia apática; es una crueldad ejercida sobre sí mismo que puede traducirse como la consigna placentera que una y otra vez repite: yo seré el presente. Si bien el presente es lo inmediato, las sensaciones del sentir romántico, el ensueño de la contemplación y la excursión al Parnaso, al Louvre en los sucesivos Salones que desde 1846 describiera; así también el presente es el ridículo, lo desproporcionado, esa serie de objetos burdos, esos elementos 
decorativos y caprichos del gusto que pueblan el mundo desencantado y que, tanto el artista como el crítico, ven moverse a su alrededor simulando una danza macabra que misteriosamente repele y atrae. ¿Quién podría decir algo sobre ellos, sobre lo que habita entre la muchedumbre, pero sólo llama la atención del excéntrico, el solitario, el palmípedo extraviado? El único método crítico posible es el que busca conciliar el obsceno progreso con las bellas artes. Desde muy temprano Baudelaire se preocupa por el problema de la intelección de lo moderno, por cómo pensar la atracción y el rechazo de lo fascinante. Y sus dudas, sus interrogantes, no son sólo una provocación, son más bien una figuración del crítico:

¿Qué haría, ¿qué diría un Winckelmann moderno (los tenemos a montones, la nación rebosa), que diría frente a un producto chino, producto extraño, raro, amanerado en su forma, intenso por su color, y a veces delicado hasta el desvanecimiento? (1996, pp. 199-200).

En esa pregunta desafiante por el presente extraño, amanerado, delicado, que ya Goethe anunciara como el riesgo que correr toda weltliteratur de ser prosa del mundo, la fascinación muestra su doble cara. En la prosa ensayística es una aventura estética, el alba crítica y el crespúsculo teórico del día a día. Mientras que, en la poesía, no es más que repulsión, apatía, saturación de los nervios alterados por una mirada que va más allá de la seguridad de su ventana, y que por sobre todo transforma la inspiración en queja, el ritmo en celebración y lamento. Aun así, Baudelaire no puede sentir el pasado y 
evadirse, perderse en él para simplemente apartar de sí aquello que lo estimula y lo desconsuela; en todo caso sólo puede elogiarlo si lo hace en su condición de polvo, la ruina que cual maquillaje anacrónico trasviste el rostro del presente. Lo que linda con lo vulgar, y lo que ofrece el esplendor de aquello que una vez fuera, se transforma en la verdadera fantasmagoría moderna. El riesgo del mal gusto y el peligro de lo simplemente atemporal lo aguarda en los extremos de su propio reflejo contemporáneo. Así ante lo que Baudelaire llama "las espirales infinitas de la vida", acaso otra forma de mencionar sus propias meditaciones, sus recuerdos de lo inmediato que el rostro de una prostituta o un obrero le entregan súbitamente, no hay estética, ni filosofía o pensamiento que pueda contener justamente su evanescente ascenso o descenso hacia el presente indiferente. Baudelaire sabe que debe inventar un lenguaje; lo singular es que debe estar compuesto de imágenes y conceptos antes que de palabras; ese lenguaje debe ser un teatro en donde las figuraciones íntimas de su percepción se representen como un drama. ¿Qué otra cosa queda entonces más que la confesión del propio límite en medio de la excitación? Desde muy temprano el método crítico de Baudelaire consistió en la honestidad pura del espectador sensible y apasionado que, sobre el final, se volvería la expresión de un corazón desnudo que se viste de ingenuidad:

para escapar al horror de las apostasías filosóficas, me resigné orgullosamente a la modestia: me contenté con sentir; regresé a encontrar un asilo en la impecable ingenuidad (p. 201). 
El sentir de Baudelaire inaugura la modernidad crítica no porque sea un impulso autoritario y egotista, sino más bien porque lleva al juicio estético el programa romántico que desde el prefacio a Cromwell Víctor Hugo impulsara. "Quien dice romántico dice arte moderno", proclama Baudelaire defendiendo el predominio de lo íntimo, la aspiración infinita y el color por sobre el dibujo en los cuadros que ha visto en el salón de 1846; y aún más, ese dejo de romanticismo que no está en los temas "sino en la manera de sentir" (103). Delacroix, que es "a menudo un poeta en pintura", refleja en su procedimiento que "un cuadro debe ante todo reproducir el pensamiento íntimo del artista" (118). Habría que señalar que el sentir de Baudelaire, por momentos tan vilipendiado en lo emotivo, en lo patológico y en la reducción anecdótica, es más bien una superación del sentimentalismo. En este caso no se trata de una simple percepción que desde el afuera produce una serie de motivaciones anímicas en el interior de un sujeto, sino que más bien es todo lo contrario; sentir, dejarse ganar por la corriente eléctrica que se libera en la alteración de todo aquello que participa del presente, ya sea una ciudad que se demuele o una escultura impávida en el hundimiento de su soledad, es una entrega a la imaginación creadora con la cual el sujeto busca los estímulos secretos que se ocultan en el bosque de las correspondencias. De este modo Baudelaire transformó el sentir en un principio analítico de su pensamiento estético; hizo de la experiencia ante lo extraño una aspiración a lo abstracto, y con sólo señalar que 
es preciso que el crítico, el espectador, opere en sí mismo una transformación algo misteriosa, y que, por un fenómeno de la voluntad actuando sobre la imaginación, aprenda por sí mismo a participar en el medio que ha dado origen a esta insólita floración (p. 200).

pudo justamente revertir el signo negativo del progreso en el ejercicio fáustico del cosmopolitismo. Pero ¿de dónde provenía el poder de esa alquimia para perseguir "la expansión de las cosas infinitas" (1974, p. 40) que permitía ver en los prostíbulos catedrales y en las fábricas pilas bautismales hasta el extremo mismo de hacer del presente una intensa mirada melancólica?

Aunque suene paradójico, el presente en Baudelaire es lo que falta, o en todo caso lo que se experimenta y se conquista por medio de esa condición faltante que el melancólico celebra. Y no sólo lo que falta en tanto que método crítico, forma o procedimiento de contemplar y disfrutar de una forma; sino también en tanto que experiencia. En 1853 el pequeño ensayo titulado "Moral del juguete", publicado en Le Monde littéraire, erige una escena mítica que puede leerse como lo que Baudelaire desea encontrar en el presente, es decir, lo que decide traer al lugar de la falta. El mismo comienza con un recuerdo de infancia. El pequeño Charles asiste con su madre a la casa de un librero y editor. Los recibe su esposa, envuelta en pieles y terciopelo, como tiempo después se vestirán las heroínas dominantes de Sacher-Masoch, aunque para él será "el hada de los juguetes". Ésta lo conduce a una habitación repleta de pequeños tesoros que el despilfarro ha atiborrado 
para la atención del niño que se ve obsequiado con la elección de uno. Lo que sigue es una maravillosa transposición de la voluntad del deseo para con el futuro crítico de arte:

Con esa admirable y luminosa prontitud que caracteriza a los niños, en quienes el deseo, la deliberación y la acción forman, por así decir, una sola facultad, por la que se distinguen de los degenerados hombres, en quienes, por el contrario, la deliberación devora casi todo el tiempo, me apoderé inmediatamente del más bonito, del más caro, del más llamativo, del más fresco, del más extraño de los juguetes (1996, p. 191).

La infancia y los juguetes son la primera iniciación en el arte. ${ }^{1}$ El juguete es el presente absoluto, es el instante sin antes ni después. No sólo por el discernimiento de formas que el pequeño Baudelaire demostró con la siguiente pregunta retórica: "¿No se encuentra allí toda la vida en miniatura, y mucho más coloreada, limpia y reluciente que la vida real?" ( $p$. 192), sino también por lo que demandan a la imaginación: en mecanismos, en formas, en hipnóticos colores, al fin y al cabo, en símbolos que están entre nuestras manos a cambio de otra cosa presuntamente real con la que el niño llena todo el horizonte de lo faltante sin percibir la diferencia misma. Imaginar gracias a la fascinación que despierta el juguete sería entonces la forma de traer lo real a la infancia, de hacer de la infancia lo más real de cualquier experiencia. Sin embargo, hay

1 Del mismo modo la infancia es también una forma de filosofía que acontece en su durée, en su ser-vivida, como lo señala Agamben: "La vida del niño, como resulta, en vez de parecer completamente dividida en pequeños hechos y episodios faltos de sentido e historia (como la vida de los primitivos), permanece inolvidable, la cifra de una historia mayor" (2012, p. 32). 
otra observación bastante precisa de Baudelaire, y es que el juguete se acaba en sí mismo, ya sea por la destrucción que el niño le dispensa para develar el misterio de su funcionamiento, o por la negación trascendente que radica en su inutilidad. El juguete acaba en sí mismo porque si es el presente debe necesariamente acabar en él, debe dejar traslucir su aniquilación. La economía negativa que el juguete produce se superpone a la promesa de felicidad del arte. El juguete es el tiempo susceptible de perderse, de destruirse de volverse justamente promesa de felicidad cuando ya no podemos jugar. Frente a los padres que no regalan juguetes, pues no conciben un medio poético de pasar el tiempo, hasta los padres que los conciben como objetos de adoración, el juguete es la alegoría del arte con la cual Baudelaire increpa la habitación vacía de la burguesía y a los mismos artistas:

Hay niños que hacen lo mismo: no usan sus juguetes, los economizan, los ponen en orden, hacen con ellos bibliotecas y museos, y de vez en cuando los enseñan a sus amiguitos rogándoles no tocar (p. 195).

Baudelaire parce decirnos que al extraviar nuestros juguetes y con ellos la imaginación de lo que falta, es decir el presente, nos queda como un consuelo la extraña fascinación del arte para poder recuperar ese presente. 
"Lo bello es siempre extraño" señala Baudelaire citando a Poe, quien se convertirá en el espejo donde mirarse hasta confundir admiración con autocompasión en una sola pregunta sin respuesta; una pregunta que, por otro lado, está pronunciada en un sentido profético: “Existen, pues, almas sagradas, dedicadas al altar, condenadas a dirigirse a la muerte y a la gloria a través de sus propias ruinas?" (1984, p. 210). Como una reiteración, o más bien como una trágica afinidad, la agonía de Poe -el escritor moderno al cual la sociedad expulsa hasta transformarlo en las ruinas de un esplendor que Baudelaire traduce literal y metafóricamente en él mismo- se transformará en el itinerario vital del presente. De algún modo el proceso a Las flores del mal replicará la experiencia de una obra para el futuro sin público en el presente. La soledad de Poe en la Norteamérica del progreso es entonces un antecedente de la soledad de espíritu experimentada por Baudelaire en la capital del siglo XIX. Sin embargo, lo original es que esa experiencia ahora se vuelve reflexión. Si Poe en absoluta soledad pensó los alcances del método compositivo; Baudelaire, rodeado de acólitos o prefiguraciones de una escuela, fue un paso más allá y pensó las consecuencias de éste en la vida y la obra de Poe. Por eso, antes que una obra Poe es un destino; y lo es por la experiencia de soledad e incomprensión que excede al presente; también lo es por encarnar la perfección superlativa que en sí lleva el germen de la perdición, pues el genio que lo habita, con su simple aspiración espiritual, desnuda la descomposición del mundo 
que lo condena y lo rechaza. En el infierno burgués, la extrañeza que muestra ese mismo infierno es imperdonable.

La extrañeza es justamente lo que más interesa a Baudelaire; está convencido de que sin ella no hay belleza y mucho más aún, sin ella no hay distinción, melancolía de la aristocracia o promesa de felicidad como lo señala en El pintor de la vida moderna. Pero la extrañeza sólo es constitutiva de la belleza próxima, de lo inmediato, de aquello que asalta la atención de un instante. No hay extrañeza en lo consagrado, no hay extrañeza en el pasado. Así podemos imaginar al autor de los Salones recorriendo las exposiciones de uno y otro año no tanto con el fin de dar cuenta del estado del arte, sino más bien con el fin de dar cuenta de la propia percepción ante lo extraño, de los mecanismos que operan en uno para reconocer y distinguir lo extraño. La belleza, término complejo y en algún punto reducido por la tradición misma de lo estético, es entonces "la cualidad esencial del presente" (2015 a , p. 134) pero sólo si esa belleza es rara, si una y otra vez su cualidad remite a la fascinación del presente. ¿Cómo reconocerla? ¿En dónde encontrar justamente la distinción que hace a lo bello como algo circunstancial y particular antes que general? La fascinación por la moda puede ser en un primer momento la clave de esa distinción. Para Baudelaire la moda tiene un sentido progresivo; como capas y capas de una continuidad que unen lo que perdura, lo que jamás pasa de moda, y lo que cambia, lo que delata la presencia de la moda. Sin embargo, lo bello en Baudelaire se adelanta en el recubrimiento que suponen esas capas de sentido que no evaden el tiempo y la reificación fetichista; lo bello va más allá de su condición 
envolvente, va mucho más allá también de los pliegues de un vestido o de los relieves de un rostro montado sobre el arte del maquillaje que Baudelaire observara en las mujeres como un teatro de las costumbres. Lo bello no es más que lo subjetivo en sí; pero no lo subjetivo como una simple derivación de lo biográfico, sino lo subjetivo como algo que corresponde a una construcción de sentido que vale tanto por su estructuración interna e inmanente, como por su vínculo externo y trascendente; por lo que Baudelaire detecta como temperamento, el elemento fundamental que sirve para complejizar el presente: "La porción eterna de belleza estará al mismo tiempo velada y expresada, si no por la moda, al menos por el temperamento particular del autor" (136).

Por detrás de la vida de Poe, de su particular temperamento, está expresada, sin lugar a duda, la porción eterna de belleza que interesa a Baudelaire. Esa porción no está sólo en las obras, está también en el método, en la aplicación rigurosa con la cual la razón traduce visiones que se objetivan en la eficacia de la conmoción, el arrebato, el deslumbramiento. Pero lo sobrenatural, el terror, los horrores de Poe no son nada sin la claridad de su imaginación, la cual es capaz de disecarse en procedimientos y justificaciones; y a la vez, su imaginación creadora, hábil también para develar el misterio, o transparentar los efectos hipnóticos de un poema como El cuervo, no es nada sin el hallazgo de esa "voluptuosidad de olvido en las botellas" (1984, p-. 233). Lo moderno requiere entonces de una doble actitud, la cual traerá como resultado el fin de la pasividad nerviosa del artista. Por un lado, la predisposición a la novedad, que sólo el niño manifiesta en su 
perfecta embriaguez, a la cual Baudelaire llama "infancia recuperada" (2015 , p. 143); pero también, por otro lado, en el paso más allá que va de la contemplación hacia la capacidad nada más y nada menos que "para aprender los medios de expresar la vida" (p. 152). La oscilación entre la visión y el método, ciertamente un equilibrio peligroso y fascinante, es el movimiento que intensifica la experiencia del presente, experiencia en la cual el artista busca "pintar y explicar de una manera impecable, impresionante, terrible, la excepción en el orden moral' (1984, p. 236).

\section{III}

La excepción moral es en sí el final del presente. Más allá de ella no queda nada, todo se deshace, se vuelve fin o delirio, afección nerviosa o silencio. La exasperación, el odio, el padecimiento de las costumbres y su transgresión -al fin y al cabo, esto son los últimos años de Baudelaire- son los caminos por los cuales se llega a la decepción. Razón por la cual la excepción moral es incomunicable para Baudelaire. No se adapta a la prosa ni mucho menos a la reiteración del ritmo poético porque justamente no hay ya nada similar a la percepción apática que busca lo bello en lo odiado. Sólo el fragmento es posible, sólo la intención recubierta de la indistinción propia asegura el deseo de poner un nombre a lo que ya no tiene nombre.

Baudelaire llega a Bélgica en 1864, permanece en Bruselas durante dos años, poco tiempo después morirá mudo y 
hemipléjico. Pero llega a Bélgica persiguiendo el fantasma de Hugo, la necesidad de dinero y un castigo autoimpuesto: dar en el Círculo de Artistas una serie de conferencias que le aseguren el contacto con editores, la realización futura de sus obras completas y acaso la escritura de un nuevo libro. El fracaso de Baudelaire es relativo, Bélgica era por ese tiempo esa parte del presente que fastidia: una reiteración de costumbres, el desaliño en el orden de la moda, la prueba de la soledad en la multitud impuesta a la moral del artista, y hasta la cerveza imposible de beber. Sin embargo, si en el presente la fascinación se corresponde con la extrañeza, en ese mismo presente la decepción llega con la experiencia del horror. Bélgica es esa experiencia, y el libro soñado por Baudelaire debía ser el modo no sólo de señalar ese horror, sino también de exorcizarlo del presente. Por ejemplo, para Charles Asselineau, suerte de amigo y primer biógrafo, "el odio de Baudelaire hacia Bélgica, o más bien hacia los belgas, llegó poco a poco a la exasperación; fue un odio con el que no tuvieron nada que ver los desengaños de los primeros días" (2004, p. 69). La exasperación es la forma más extrema de lo moderno. En ella hay algo de odio, incomprensión, pero también de singularidad. El exasperado es el sujeto del presente vuelto intensidad del odio, el exasperado es el sujeto que hace de la decepción la forma de intelección del presente odiado. ¿No es acaso la exasperación la verdadera prueba del artista moderno? ¿No es en el camino de la exasperación donde se traza la orientación hacia la excepción moral?

Los fragmentos de Pobre Bélgica no sólo consisten en apuntes del odio baudeleriano, esbozos en defensa de un soñador ante 
la pesadilla; sino que también son una doble forma de cristalizar el presente en su etapa final. Por un lado, la decepción objetiva del insulto: las mujeres belgas no son ni la copia imperfecta de las prostitutas francesas, ni mucho menos la elegancia sobrenatural de las damas de bulevar; son simples cuerpos que aún no han ascendido al pudor, son meonas: "la madre belga, en su letrina (con la puerta abierta) juega con su hijo y sonríe a los vecinos" (2015b, p. 44). Al mismo tiempo en esa decepción un sentido superlativo de la abyección comienza a desplazar el predominio estético de lo extraño, comienza a dejar de lado la fascinación por lo raro en virtud de un desprecio conservador: "La cerveza de Bruselas está sacada de la gran letrina, el Senne; es una bebida extraída de los excrementos de la ciudad sometidos al aparato divisor. Por lo tanto, desde hace siglos la ciudad bebe su orina" (p. 39). Pero por otro lado está también la decepción subjetiva del castigo. En lo más profundo de él, Baudelaire desea padecer Bélgica, añora satisfacer su "espíritu de pequeña ciudad"; para ello observa el presente no en busca de extrañezas sino más bien en busca de hastío, pero un hastío autoimpuesto que le permita ser el colmo de lo extraño:

$\mathrm{Si}$ se permanece aquí durante mucho tiempo, todo el mundo pregunta. «¿El señor se ha expatriado sin duda?"». Tan difícil les resulta comprender que se puede permanecer aquí por placer y vivir voluntariamente con ellos. Siempre tuve ganas de responder: «Sí, señor, porque asesiné a mi padre y lo devoré sin hervirlo». Pero me creerían. El belga es como el ruso, teme que lo examinen. Quiere ocultar sus llagas (p. 68). 
La excepción moral del artista es el odio, sin él no hay presente. Odiar el presente es abrazarlo en su totalidad. El final de Baudelaire no puede ser entonces de otra forma; desencantado, decepcionado, al borde de condenar el presente, mirando las iglesias barrocas de Namur, se desploma en el momento de esplendor de su propia ruina.

\section{Referencias Bibliográficas}

Agamben, G. (2012). "Por una filosofía de la infancia", en Teología y lenguaje, Buenos Aires: Las Cuarenta.

Asselineau. C. (2004). Charles Baudelaire. Su vida y su obra, Valencia: Pre-textos.

Baudelaire, C. (2015a). El pintor de la vida moderna, Barcelona: Visor.

---. (2015b). Pobre Bélgica, Buenos Aires: Losada.

---. (1996). “Exposición Universal -1855- Bellas Artes”, “¿Qué es el romanticismo?", "Eugène Delacroix", "Moral del juguete", en Salones y otros escritos sobre arte, Madrid: Visor, 1996.

---. (1984). "Edgard Poe, su vida y sus obras", en Escritos sobre literatura, Barcelona: Editorial Bruguera.

---. (1974). Las flores del mal, Barcelona: Libros Río Nuevo. 